\title{
Approach-avoidance conflict behavior as a function of prior experience with mild or intense electric shock stimulation
}

\author{
WILLIAM TERRIS ${ }^{1}$ AND STANLEY WECHKIN \\ NORTHWESTERN UNIVERSITY MEDICAL SCHOOL
}

Albino rats were subjected to a series of either intense $(.80 \mathrm{ma})$ or mild $(.25 \mathrm{ma})$ electric shock and were later tested in a conflict situation with the same level of shock serving as the aversive stimulus. Two no-prior-shock control groups were also tested in the conflict situation under either mild or intense shock. Both prior shock groups were more sensitive to subsequent shock than were their respective no-shock control groups.

In recent years an extensive amount of research (e.g., Kurtz \& Walters, 1962; Pearl, Walters, \& Anderson, 1964; Walters \& Rogers, 1963) has tested the hypothesis that "...experiences of intense fear predispose animals to react with increased fear in subsequent encounters with aversive stimuli" (Kurtz \& Walters, 1962, p. 1078). Animals subjected to intense electric shock have shown greater sensitivity to electric shock encountered in subsequent conflict situations. This effect is long lasting, with shocked rats reacting more fearfully when tested a year later (Walters \& Rogers) and the effect is not limited to shock since it has been found that shocked animals were also more sensitive to loud noises in a subsequent conflict situation (Pearl, Walters, \& Anderson, 1964).

Other experimenters, however, have reported conflicting results. The majority of the infantile stimulation studies (e.g., Denenberg, 1963) have found that electric shock reduces subsequent emotionality. Miller (1960) and Steckle \& O'Kelley (1941) have found that electric shock stimulation of adult rats decreases subsequent responsiveness to electric shock experienced in a conflict situation.

This experiment was prompted by the observation that the experiments using intense shock (e.g., Kurtz \& Walters) have generally found sensitization while studies reporting reduced responsiveness have used milder shock (e.g., Steckle \& O'Kelley). The hypothesis was that strong electric shock experiences would result in sensitization to subsequent strong electric shock while mild shock experiences would result in adaptation to subsequent mild shock.

\section{Method}

The Ss were 43 male experimentally naive SpragueDawley albino rats approximately 85 days old at the start of the experiment. The main apparatus consisted of a shock box and a covered runway. The shock box, designed to minimize the possibility of stimulus generalization from the shock box to the runway apparatus, was constructed with rounded sides and with rectangular brass bars for the floor. In addition, the Ss were shocked in darkness and in a room which was different from the one in which the runway training took place. The runway was $36 \mathrm{in.} \mathrm{long,} \mathrm{4-1/2} \mathrm{in.} \mathrm{high,} \mathrm{and} \mathrm{4-1/2} \mathrm{in.} \mathrm{wide}$ and was constructed of wooden walls painted flat gray with No. 16 size wire mesh serving as the ceiling and the first 24 in. of the runway floor. The last 12 in. of the runway consisted of $1 / 8-i n$. brass rods spaced $1 / 2$ in. apart.

The Ss were placed on a 23-hr. food deprivation schedule on the first day of the experiment, and this schedule was maintained throughout the experiment. On day 7, all Ss were removed individually from their home cage and placed into a shock box for a total of $6 \mathrm{~min}$. The Ss were randomly assigned to one of four treatment groups, with one group receiving $601-\mathrm{sec}$. .80 ma electric shocks, another group receiving an equal number of .25 ma shocks, and the last two groups receiving no electric shock. The shocks were administered after the $S$ had been in the shock box $30 \mathrm{sec}$. and were spaced 2-6 sec. apart with a mean interval of $4 \mathrm{sec}$. A Grason-Stadler E 6070B shock apparatus and scrambler served as the shock source.

On the eighth day, approach training began with all Ss given two trials per day for the next 11 days. The procedure involved placing the animals into the start box and recording the amount of time taken to reach the food and begin eating (consummatory latency). The Ss were allowed $30 \mathrm{sec}$. to eat and were then removed. On the 19th day, avoidance training began with either a 1-sec. $.80 \mathrm{ma}$ or $.25 \mathrm{ma}$ electric shock being introduced when the $\mathrm{S}$ began to eat the food. The highhigh $(\mathrm{HH})$ group $(\mathrm{N}=12)$ received high shock $(.80 \mathrm{ma})$ in the shock box and in the runway while the low-low (LL) group ( $\mathrm{N}=11)$ received low shock $(.25 \mathrm{ma})$ in the shock box and in the runway. The animals not receiving shock in the shock box were randomly assigned to one of two groups, with one tested under high shock and the other under low shock. These were the none-high (NH) group $(\mathrm{N}=10)$ and the none-low $(\mathrm{NL})$ group $(\mathrm{N}=$ 10). During avoidance training, all Ss were given one trial per day and allowed $2 \mathrm{~min}$. in which to begin eating. After the shock was applied, the Ss were allowed $3 \mathrm{~min}$. to return to the food on the first avoidance trial and $2 \mathrm{~min}$. on succeeding days. The time taken to return to food and begin eating is referred to as the reconsummatory latency. 


\section{Results and Discussion}

In order to determine whether the shock box treatment on day 7 had affected the Ss' subsequent runway performance prior to the introduction of shock into the runway a Kruskal-Wallis nonparametric one-way analysis of variance was performed on the time taken to traverse the runway and begin eating (consummatory latency) on the first trial as a function of the stimulation administered in the shock box (High shock, Low shock, or No shock). A significant Chi square was obtained (Chi square $=25.93, \mathrm{df}=2, \mathrm{p}<.001)^{2}$ and further analysis with Mann-Whitney $U$ tests showed that the group of animals receiving intense shock in the shock box had significantly longer consummatory latencies than did either the Low shock $(p<.01)$ or the No shock group $(p<.01)$ while the difference between the Low shock and No shock groups was not significant $(p>.2)$. This indicates that in spite of the attempt to reduce the similarity between the shock and test apparatus, stimulus generalization probably occurred. While the stimulus situation was considerably different in the two situations, there were factors which could act as a source for stimulus generalization. Perhaps the most obvious stimuli are those associated with the experimenter, such as being handled, and all the stimuli associated with this procedure. While other studies have not found stimulus generalization effects, this may be due to their long delay between the shock box stimulation and approach training.

A Kruskal-Wallis nonparametric one-way analysis of variance of the consummatory latencies on trial 22 (the last trial of approach training before the introduction of electric shock into the runway) as a function of the three shock box stimulation conditions yielded an insignificant Chi square (Chi square $=4.79, \mathrm{df}=2, \mathrm{p}$ > $.05)$. This indicates that by the time electric shock was introduced into the runway the approach strengths of the animals did not differ significantly as a function of the treatment received in the shock box.

Since all the Ss tested with $.80 \mathrm{ma}$ shock in the runway stopped consuming by the 25th trial, analysis of the differences between the $\mathrm{HH}$ and $\mathrm{NH}$ groups was limited to the reconsummatory latencies on trial 23 and the consummatory latencies on trial 24. Mann-Whitney $\mathrm{U}$ tests of the difference between the $\mathrm{HH}$ and $\mathrm{NH}$ groups on these two measures were significant at the .05 level in both cases with the $\mathrm{HH}$ group having longer consummatory and reconsummatory latencies than the $\mathrm{NH}$ group. The median consummatory latencies for the $\mathrm{NH}$ and $\mathrm{HH}$ groups on trial 24 were $11.2 \mathrm{sec}$. and
46.5 sec., respectively, while the median reconsummatory latencies on trial 23 were 45.6 sec. and 168.8 sec., respectively.

Since all the Ss tested with .25 ma shock made consummatory responses throughout avoidance training, a median consummatory latency was obtained for each $S$ for trials 24-27, and a Mann-Whitney $U$ test was performed on the difference between the NL and LL groups. The difference between these groups was significant at the .05 level, with the NL group (Median= 1.6 sec.) having significantly lower consummatory latencies than the LL group (Median $=2.3 \mathrm{sec}$.). A similar analysis of the differences between the median reconsummatory latencies for trials 23-27 for these two groups was significant at the .02 level with the LL group (Median $=6.4$ sec.) taking significantly longer time to return to the food and begin eating than the NL group (Median = less than 1 sec.).

The results of this experiment are in agreement with the results of the studies by Kurtz and his associates and extend the findings to low as well as high levels of shock. The results are contrary to the hypothesis of adaptation to mild shock and raise the question of whether intense fear is necessary to produce sensitization to aversive stimulation. Kurtz has hypothesized that intense fear experiences produce the effect, but it is difficult to consider .25 ma shock as a stimulus which produces intense fear since the administration of this shock in the shock box rarely evoked a clearly observable sign of emotional behavior such as vocalization or defecation.

\section{References}

Denenberg, V. Early experience and emotional development. Scient. American. 1963, 208, 138-146.

Kurtz, K., \& Walters, G. The effects of prior fear experiences on an approach-avoidance conflict. J. comp. physiol. Psychol., $1962,55,1075-1078$.

Miller, N. E. Learning resistance to pain and fear: effects of overlearning, exposure and rewarded exposure in context. $J$. exp. Psychol., 1961, 60, 137-145.

Pearl, J., Walters, G., \& Anderson, D. Suppressing effects of aversive stimulation on subsequently punished behavior. Canad. J. Psychol., 1964, 18, 343-355

Steckle, L., \& $\mathbf{O}^{\prime}$ Kelley, L. Persistence of response as a function of thirst in terms of early experience with electric shock. $J$. comp. Psychol., 1941, 32, 1-9.

Walters, G., \& Rogers, J. V. Aversive stimulation of the rat: longterm effects on subsequent behavior. Science, 1963, 142, 70-71.

\section{Hotes}

1. Present address: Department of Psychology, University of Oklahoma, Norman, Oklahoma.

2. All probability statements are based upon two-tailed tests. 